9. Tschudi, M., Meier, W. N., Stewart, J. S., Fowler, C. and Maslanik, J., Polar Pathfinder Daily $25 \mathrm{~km}$ EASE-Grid Sea Ice Motion Vectors, Version 4. NASA National Snow and Ice Data Center Distributed Active Archive Center, Boulder, Colorado USA, 2019; doi:https://doi.org/10.5067/INAWUWO7QH7B (accessed on 12 February 2021).

10. Leppäranta, M., The Drift of Sea Ice, Springer, Science \& Business Media, Berlin, Germany, 2011.

11. Luo, W., Yue, Z., Jianmin, L. and Shuqin, H., China's first transArctic voyage and related expectations. Adv. Polar Sci., 2014, 26(2), 276-284

ACKNOWLEDGEMENTS. I thank the National Snow and Ice Data Center for ice motion and ice concentration data. This research received no external funding.

Received 21 March 2021; revised accepted 7 July 2021

doi: $10.18520 / \mathrm{cs} / \mathrm{v} 121 / \mathrm{i} 4 / 567-570$

\section{Characterization of granulosis viruses of sugarcane early shoot borer, Chilo infuscatellus (Snell.) and internode borer, Chilo sacchariphagus indicus (Kapur)}

\author{
M. Kannan ${ }^{1}$, N. Geetha ${ }^{2}$, K. Elango ${ }^{3}$, M. Mohan ${ }^{4}$ \\ and G. Sivakumar ${ }^{4, *}$ \\ ${ }^{1}$ Nano Science and Technology, Tamil Nadu Agricultural University, \\ Coimbatore 641 003, India \\ ${ }^{2}$ ICAR-Sugarcane Breeding Institute, Coimbatore 641 007, India \\ ${ }^{3}$ Imayam Institute of Agriculture and Technology, \\ Tiruchirappalli 621 206, India \\ ${ }^{4}$ ICAR-National Bureau of Agricultural Insect Resources, Hebbal, \\ Bengaluru 560 024, India
}

A study was undertaken to characterize the granulosis viruses (GVs) of early shoot borer, Chilo infuscatellus (Snell.) (Crambidae: Lepidoptera) and internode borer, Chilo sacchariphagus indicus (Kapur) (Lepidoptera: Crambidae) in sugarcane. Scanning electron photomicrographs revealed ovo-cylindrical occlusion bodies (OBs) of GVs in early shoot and internode borers with an average size of 425.03 and $230.21 \mathrm{~nm}$, 387.64 and $208.68 \mathrm{~nm}$ in length and breadth respectively. Transmission electron photomicrographs also showed ovo-cylindrical OBs embedded with a rodshaped virion. The average length and breadth of the virion in the $O B$ was $271.0 \times 52.6 \mathrm{~nm}, 257.0 \times 50.2 \mathrm{~nm}$

*For correspondence. (e-mail: sivakumarg.nbaii@gmail.com) for early shoot and internode borer GVs respectively. Toxicity studies with the respective GVs revealed lethal concentration values of $4.38,4.61,6.89 \mathrm{OBs} / \mathrm{mm}^{2}$ and $1.85,135.43,8045.27 \mathrm{OBs} / \mathrm{mm}^{2}$ to second, third and fourth larval instars of Chilo infuscatellus granulosis virus (ChinGV) and Chilo sacchariphagus indicus granulosis virus (ChsaGV) respectively.

Keywords: Early shoot borer, granulosis viruses, internode borer, occlusion bodies, sugarcane, toxicity.

INSECT pests are the key constraint in sugarcane production as they damage all stages of the crop. Early shoot borer, Chilo infuscatellus Snellen and internode borer, Chilo sacchariphagus indicus (Kapur) are the most economic pests of sugarcane in India and cause 33\%, 35\% in yield and 3\%, 3.07\% in sugar recovery respectively ${ }^{1}$. C. infuscatellus is commonly known as shoot borer in the North Indian sugarcane belt and as early shoot borer in peninsular India ${ }^{2}$. High usage of chemical insecticides in its management has led to changes in the biology and reproductive potential of the pest and development of insecticide resistance ${ }^{3}$. The microbial biopesticide, granulosis virus $(\mathrm{GV})$ belonging to the Baculoviridae family is an effective alternative for managing sugarcane borers. Natural occurrences and high pathogenicity of Chilo infuscatellus granulosis virus (ChinGV) and Chilo sacchariphagus indicus granulosis virus (ChsaGV) to all the larval instars, post-larval stages under laboratory and field conditions have been reported by several workers ${ }^{4-6}$. Laboratory studies proved that early instars of internode borer were more susceptible to $\mathrm{GV}$ than late instars. First and second instar larvae were found to be highly susceptible to ChinGV and mortality ranged from $61.9 \%$ to $100 \%$ (ref. 5). Detailed information is not available on the characterization of GVs infecting sugarcane borers. Thus in the present study, we characterize the GVs for the development of green biopesticide formulation to manage sugarcane borers.

Larvae of shoot and internode borers were collected from sugarcane fields of Coimbatore and its surroundings in Tamil Nadu, South India. The insects were reared on sugarcane shoot bits or internode bits. The infected larvae became restless and fed voraciously in the early stage of infection. They appeared robust with pale integument. As the infection progressed, the larvae became lethargic and ceased feeding. During rearing, larvae showing characteristic symptoms of infection with $\mathrm{GVs}$ were isolated and reared separately. The skin of the moribund larvae turned white, except in the intersegmental zone. Dead larvae were collected and put in individual sterile vials. Cadavers were labelled individually and used for extraction of GVs. Occlusion bodies (OBs) of GVs were extracted from the virosed larvae according to the standard procedure ${ }^{7}$ and stored at $4^{\circ} \mathrm{C}$ till further use. The viruses were confirmed by the presence of OBs in the discharged 

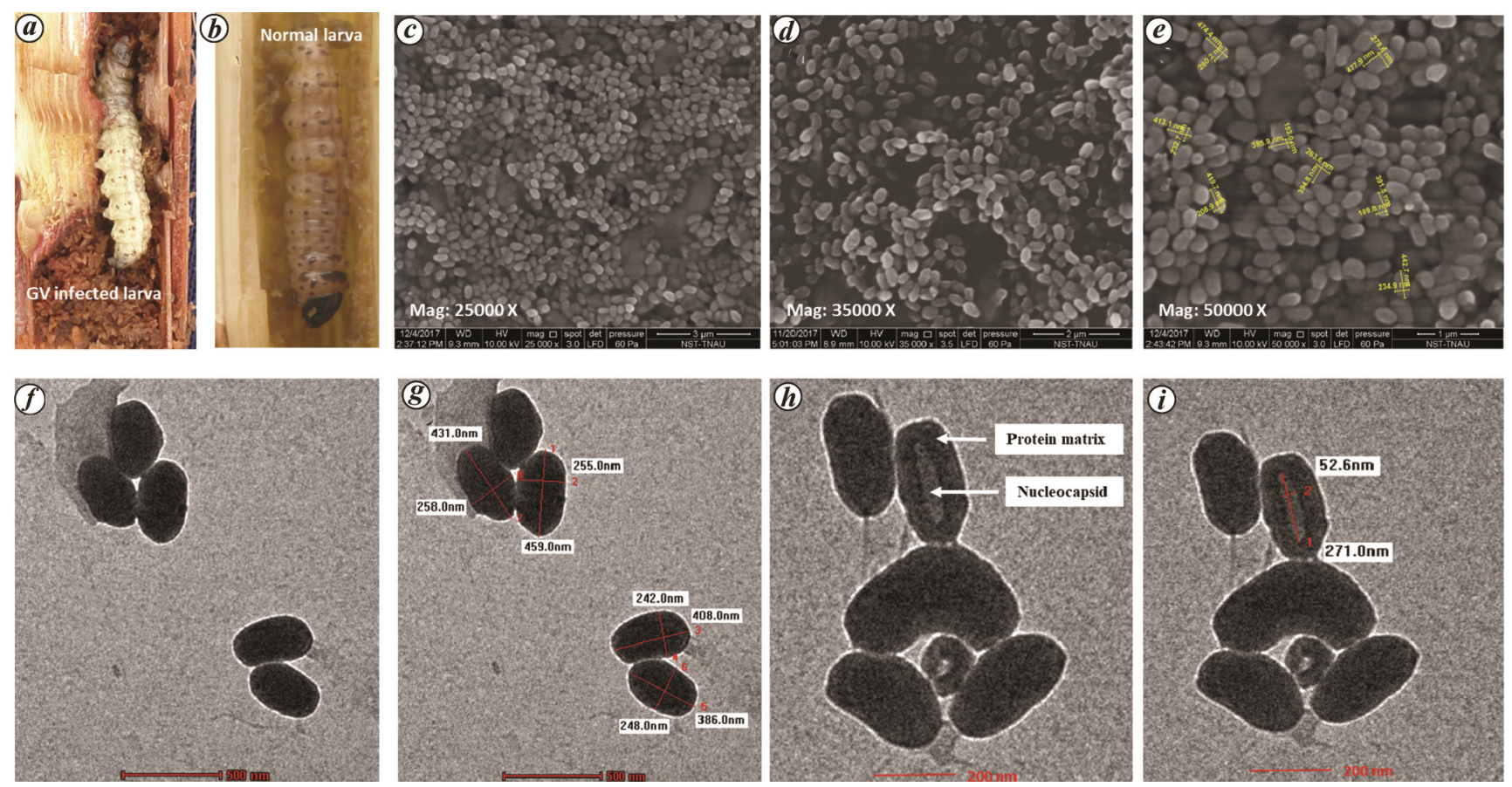

Figure 1. $\boldsymbol{a}$, Granulosis virus (GV)-infected larva of Chilo infuscatellus. $\boldsymbol{b}$, Normal larva of $C$. infuscatellus. $\boldsymbol{c}-\boldsymbol{e}$, SEM of ovoid-shaped occlusion bodies (OBs) of $C$. infuscatellus GV at magnification $(\boldsymbol{c}) 25,000 \times,(\boldsymbol{d}) 35,000 \times$ and $(\boldsymbol{e}) 50,000 \times \boldsymbol{f}, \boldsymbol{g}$, TEM of ovo-cylindrical OBs at magnification $500 \mathrm{~nm} . \boldsymbol{h}, \boldsymbol{i}$, TEM of OBs with a singly embedded, rod-shaped nucleocapsid virion.

body fluids from the individual infected larvae under phase contrast microscopy (400×; Olympus BX 41 from Japan).

Morphological characterization of the extracted OBs of GVs was done using the standard method ${ }^{8}$, and described by scanning electron microscopy (SEM) and transmission electron microscopy (TEM) available at the Tamil Nadu Agricultural University, Coimbatore. Further, the size and shape of OBs and nucleocapsid virion were measured from the electron photomicrographs.

Larval cultures of both borers were maintained on sugarcane shoot bits in the laboratory (with a mean temperature of $27^{\circ} \mathrm{C}, 60 \%$ relative humidity $(\mathrm{RH})$ and with a photoperiod of $14: 10 \mathrm{~L}: \mathrm{D})$. Bioassays were conducted with three larval instars (II, III and IV) of shoot and internode borers according to the procedure described by Subramanian et al. ${ }^{7}$. Around 40 larvae per dose or treatment and starting with a concentration of $2.0 \times 10^{9}$, $2.0 \times 10^{8}$ and $2.0 \times 10^{7} \mathrm{OBs} \mathrm{ml}^{-1}$ as the highest dose tested for IV, III and II instars respectively, with a control (40 larvae fed by an equal quantity of distilled water). Each larva was fed with $1 \mu \mathrm{l}$ of OBs, dispensed through a Hamilton glass syringe, applied to individual larva per os holding the head capsule. As the larva swallowed up the liquid, it was transferred to the sugarcane shoot/internode bits placed in filter paper-lined plastic boxes $(200 \mathrm{ml}$ capacity). The shoot/internode bits were changed manually on alternate days to provide fresh feed. Each dose was repeated four times and each replication had 10 larvae. The mortality of larvae was observed and recorded daily up to nine days of post treatment. Bioassays were carried out thrice and the pooled larval mortality data obtained were subjected to probit analysis using the standard POLO software ${ }^{9}$ to calculate the lethal concentration values $\left(\mathrm{LC}_{50}\right)$ of different larval instars of the test insect.

Discharged larval body fluid of infected larvae was observed under a phase-contrast light microscope. It showed a large number of ovo-cylindrical virus particle entities similar to the OBs of GVs. SEM photomicrographs revealed the ovo-cylindrical OBs of GVs in both early shoot and internode borers with an average size of about $425.03 \times 230.21 \mathrm{~nm}$ and $387.64 \times 208.68 \mathrm{~nm}$ in length and breadth respectively (Figures 1 and 2). TEM studies also revealed the size of the singly embedded, rod-shaped nucleocapsid virion protected by a tough proteinaceous matrix within the OBs in early shoot borer (271.0 and $52.6 \mathrm{~nm}$ in length and breadth respectively) (Figure 1) and internode borer $(257.0$ and $50.2 \mathrm{~nm}$ in length and breadth respectively) (Figure 2). The presence of these nucleocapsid virion structures in GVs is in confirmation with the results of Kathleen et al. ${ }^{10}$ in Plodia interpunctella. Comparing the average size of the GVs in both borers, the ovo-cylindrical OBs and singly embedded, rod-shaped nucleocapsid virion within the OBs were larger in the GVs of early shoot borer and relatively smaller in case of the internode borer. The results are in accordance with the findings of Sciocco-Cap et al. ${ }^{11}$ in Epinotia aporema GV, where the OBs were reported as ovoid-shaped and of similar size $(466 \mathrm{~nm})$ with single, rod-shaped virion $(226 \mathrm{~nm})$. Likewise, ovoid-shaped GVs 

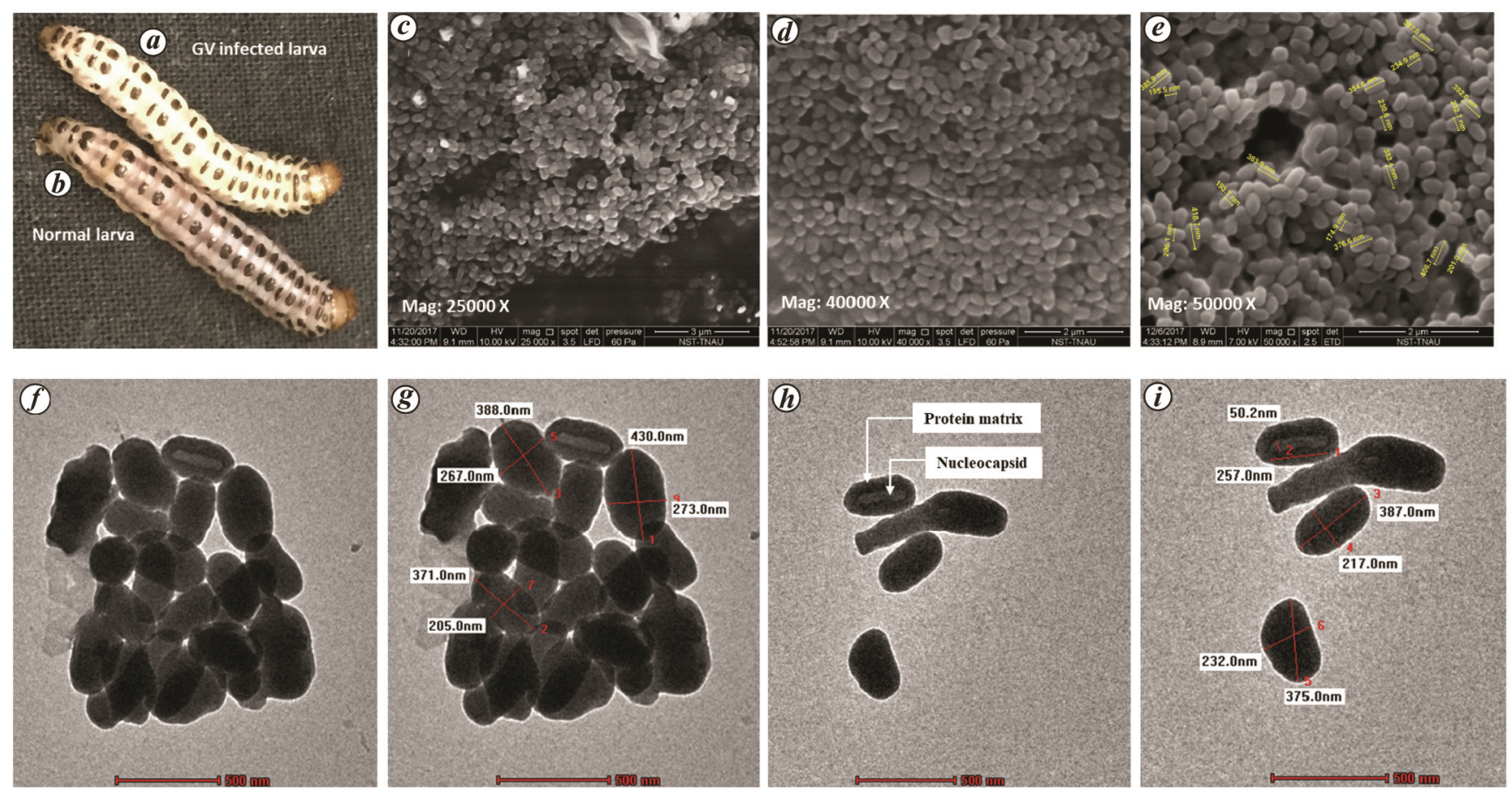

Figure 2. $\boldsymbol{a}$, GV-infected larva of Chilo sacchariphagus indicus. $\boldsymbol{b}$, Normal larva of C. sacchariphagus indicus. $\boldsymbol{c}-\boldsymbol{e}$, SEM of ovo-cylindrical OBs of $C$. sacchariphagus indicus GV at magnification $(\boldsymbol{c}) 25,000 \times,(\boldsymbol{d}) 35,000 \times$ and $(\boldsymbol{e}) 50,000 \times, \boldsymbol{f}, \boldsymbol{g}$, TEM of ovoid-shaped OBs at magnification $500 \mathrm{~nm} . \boldsymbol{h}, \boldsymbol{i}$, TEM of OBs with a singly embedded, rod-shaped nucleocapsid virion.

Table 1. Bioassay of ChinGV and ChsaGV against sugarcane early shoot borer and internode borer

\begin{tabular}{|c|c|c|c|c|c|c|c|}
\hline \multirow[b]{2}{*}{ Granulovirus } & \multirow[b]{2}{*}{$\begin{array}{l}\text { Larval } \\
\text { instar }\end{array}$} & \multirow[b]{2}{*}{$\begin{array}{c}\mathrm{LC}_{50} \\
\left(\times 10^{1} \mathrm{OBs} / \text { larva }\right)\end{array}$} & \multicolumn{2}{|c|}{$95 \%$ confidence limit } & \multirow[b]{2}{*}{ Slope } & \multirow[b]{2}{*}{$\chi^{2 *}$} & \multirow[b]{2}{*}{$\begin{array}{c}\text { Degree of } \\
\text { freedom }\end{array}$} \\
\hline & & & $\begin{array}{c}\text { Lower } \\
\left(\times 10^{1} \mathrm{OBs} / \text { larva }\right)\end{array}$ & $\begin{array}{c}\text { Upper } \\
\left(\times 10^{1} \mathrm{OBs} / \text { larva }\right)\end{array}$ & & & \\
\hline \multirow[t]{3}{*}{ ChinGV } & II & 4.38 & 2.23 & 8.20 & 1.82 & 4.21 & 3 \\
\hline & III & 4.61 & 2.14 & 9.56 & 2.06 & 3.90 & 3 \\
\hline & IV & 6.89 & 3.36 & 15.82 & 1.58 & 7.02 & 3 \\
\hline \multirow[t]{3}{*}{ ChsaGV } & II & 1.85 & 0.94 & 4.68 & 1.64 & 6.90 & 3 \\
\hline & III & 135.43 & 2.953 & 614.66 & 2.10 & 5.83 & 3 \\
\hline & IV & $8,045.27$ & 275.557 & 31,833 & 1.92 & 4.65 & 3 \\
\hline
\end{tabular}

*In each case $\chi^{2}$ value from the goodness-of-fit test was less than the tabular value $(P=0.05)$, indicating that the data fit the probit model.

have been reported in Achaea janata ${ }^{12}$, Spodoptera frugiperda $a^{13}$ and Diatraea saccharalis ${ }^{14}$.

Bioassay studies revealed instar-dependent larval mortality pattern. Larval mortality was observed in second, third and fourth instars of C. infuscatellus and C. sacchariphagus indicus. The assessed $\mathrm{LC}_{50}$ values for the second, third and fourth instars of ChinGV larva were $4.38,4.61$ and $6.89 \mathrm{OBs} /$ larva respectively. In the case of ChsaGV, the $\mathrm{LC}_{50}$ values were $1.85,135.43$ and 8045.27 OBs/larva for the second, third and fourth larval instars respectively (Table 1). Our findings are in accordance with those reported in the literature for E. aporema $\left(\mathrm{LC}_{50}\right.$ to fourth instar larvae was 4000 granules per larva $)^{11}$, S. frugiperda $\left(\mathrm{LC}_{50}\right.$ to second instar larvae was $\left.4.5 \times 10^{5} \mathrm{OBs} / \mathrm{ml}\right)^{13}$ and $D$. saccharalis $\left(\mathrm{LD}_{50}\right.$ to third instar larvae was $42.30 \mathrm{OBs} /$ larva) ${ }^{14}$.
This study presented results of the characterization of GVs of sugarcane early shoot borer and internode borer. Electron microscopy studies revealed that the OBs of both GVs appeared as ovo-cylindrical in shape and each $\mathrm{OB}$ was embedded with a rod-shaped virion protected by a tough proteinaceous matrix. $\mathrm{LC}_{50}$ values of $4.38,4.61$, 6.89 OBs larva, $1.85,135.43,8045.27$ OBs larva were recorded against the second, third and fourth larval instars of ChinGV and ChsaGV respectively.

1. Srikanth, J., Salin, K. P. and Jayanti, R., Sugarcane pests and their management. Sugarcane Breeding Institute (ICAR), Coimbatore, 2012, p. 91.

2. Shyamrao, I. D. and Kumar, A., Sugarcane borers: a major threat to sugarcane production in India and their management. Biotica Res. Today, 2020, 2, 225-228.

CURRENT SCIENCE, VOL. 121, NO. 4, 25 AUGUST 2021 
3. Moscardi, F., Assessment of the application of baculoviruses for control of Lepidoptera. Annu. Rev. Entomol., 1999, 44, 257-289.

4. Melamed-Madjar, V. and Raccah, B., The trans-stadial and vertica transmission of a granulosis virus from the corn borer, Sesamia nonagroides. J. Invertebr. Pathol., 1979, 33, 259-264.

5. Easwaramoorthy, S. and Santhalakshmi, G., Efficacy of granulosis virus in the control of shoot borer, Chilo infuscatellus Snellen. J. Biol. Control, 1988, 2, 26-28.

6. Rao, N. V. and Babu, T. R., Field efficacy of granulosis virus for the control of sugarcane early shoot borer, Chilo infuscatellus Snellen. J. Biol. Control, 2005, 19, 145-148.

7. Subramanian, S., Rabindra, R. J. and Sithanantham, S., Genetic and biological variations among Plutella xylostella granulovirus isolates. Phytoparasitica, 2008, 36, 220-230.

8. Sivakumar, G. et al., Isolation and characterization of indigenous nucleopolyhedrovirus infecting new invasive Fall armyworm Spodoptera frugiperda (J.E. Smith) (Lepidoptera: Noctuidae) in India. Curr. Sci., 2020, 119, 860-864.

9. Polo-PC, User's guide to probit or logit analysis. LeOra Software, Berkeley, 1994

10. Kathleen, A., Tweeten, L. A., Bulla, J. R. and Richard, A. C., Isolation and purification of a granulosis virus from infected larvae of the Indian Meal Moth, Plodia interpunctella. Appl. Environ. Microbiol., 1977, 34, 320-327.

11. Sciocco-Cap, A., Parola, A. D., Goldberg, A. V., Ghiringhelli, P. D. and Romanowski, V., Characterization of a granulovirus isolated from Epinotia aporema Wals. (Lepidoptera: Tortricidae) larvae. Appl. Environ. Microbiol., 2001, 67, 3702-3706.

12. Naveen Kumar, P., Prasad, Y. G., Prabhakar, M., Phanidhara, A. and Venkateshwarlu, B., Granulovirus of semilooper, Achaea janata L. (Lepidoptera: Noctuidae): its bioefficacy and safety in mammalian toxicity tests. J. Biol. Control, 2013, 27, 99-104.

13. Cuartas, P., Barrera, G., Barreto, E. and Villamizar, L., Characterization of a Colombian granulovirus (Baculoviridae: Betabaculovirus) isolated from Spodoptera frugiperda (Lepidoptera: Noctuidae) larvae. Bio. Sci. Tech., 2014, 24, 1265-1285.

14. Ardisson-Araújo, D. M. et al., Betabaculovirus encoding a gp64 homolog. BMC Genomics, 2016, 17; https://doi.org/10.1186/ s 12864-016-2408-9

Received 25 May 2021; revised accepted 14 June 2021

doi: $10.18520 / \mathrm{cs} / \mathrm{v} 121 / \mathrm{i} 4 / 570-573$

\section{Evaluation of probability distribution functions applied to tree diameter in a mixed uneven Kiker (Robinia pseudoacacia) stand of Kashmir Himalaya, India}

\author{
Tariq H. Masoodi ${ }^{1}$, Immad A. Shah ${ }^{2}$, \\ Meraj U. Din Dar ${ }^{2, *}$, Parvez A. Sofi ${ }^{1}$ and \\ Javeed A. Mugloo ${ }^{1}$ \\ ${ }^{1}$ Faculty of Forestry, Sher-e-Kashmir University of Agricultural \\ Sciences and Technology of Kashmir (SKUAST-K), \\ Benhama 191 202, India \\ ${ }^{2}$ Division of Silviculture and Agroforestry, SKUAST-K, \\ Ganderbal 191 201, India
}

Probability distribution is of significance to predict tree distribution and estimate productivity in different ages as well as thinning out in forest stands to ensure optimized and stable stands. Statistical probability distributions, viz. lognormal, Weibull, exponential and gamma were used to fit tree-diameter data generated from the Manasbal forest stand of Kashmir Himalaya, India containing a heterogeneous population of trees with the objective to determine the best probability distribution of tree diameter. To estimate the parameters of the fitted distributions, the method of maximum likelihood was used. The various distributions were evaluated using different goodness-of-fit tests, viz. Kolmogorov-Smirnov, Cramer-von Mises and Anderson-Darling statistics, and the best distribution pertaining to the forest stand was ascertained. Lognormal distribution fitted the data well and could be used in modelling, planning and scheduling the forest stand in the study region.

Keywords: Diameter class, goodness-of-fit statistics, forest stands, probability distribution function, Robinia pseudoacacia.

THE genus Robinia is noteworthy for its numerous uses. Black locust (Robinia pseudoacacia) is part of the Leguminosae family and is known locally as 'Kiker', in Jam$\mathrm{mu}$ and Kashmir, India. It is a rapidly growing species, making it a primary source of biomass fuel in the region. In many native forests where it occurs, $R$. pseudoacacia dominates early forest regeneration ${ }^{1}$. It is a spiny, deciduous tree of medium size, reaching a height of 25-30 mt and a diameter of $80-90 \mathrm{~cm}$ under favourable conditions. Models of forest simulation have been widely used to predict future stand structure. Tree-diameter distribution plays a vital role in simulation modelling. Different probability distributions are being used extensively to model the diameter of trees in the forest stands. Some of the

*For correspondence. (e-mail: mihraj.dar@gmail.com) 